\title{
Spectrophotometric determination of cisplatin, carboplatin and oxaliplatin in pure and injectable dosage forms.
}

\author{
Muhammad Munawar Hayat ${ }^{1}$, Muhammad Sohail ${ }^{1}$, Muhammad Ashraf ${ }^{2}$ \\ ${ }^{1}$ Primary and Secondary Healthcare Department, Government of the Punjab, Lahore, Pakistan \\ ${ }^{2}$ Department of Chemistry, The Islamia University of Bahawalpur, Bahawalpur, Paki stan
}

\begin{abstract}
Objective: A simple and reproducible spectrophotometric method was developed for the estimation of cisplatin, carboplatin and oxaliplatin in pure and injectable dosage forms.

Method: The method is based on the reaction of platinum drug with 1,10-phenanthrolene in the presence of ferric chloride, which formed a red coloured complex that exhibited maximum absorption at $510 \mathrm{~nm}$. The reaction is selective for platinum based drugs and obeys the Beer's law for cisplatin from 0.25-6.0 $\mu \mathrm{g}$, carboplatin 7.5-180 $\mu$ g and oxaliplatin 0.5-12.0 $\mu \mathrm{g}$. The accuracy of the developed method for cisplatin, carboplatin and oxaliplatin was $98.6 \%, 100.3 \%$ and $101.1 \%$, whereas RSD (\%) is of 1.1 , 1.3 and 1.8 , respectively.

Result: The standardization and validation of analytic method was evaluated by the parameters like linearity, accuracy, precision and sensitivity.

Conclusion: The method is useful for the determination of these drugs in pure and dosage forms.
\end{abstract}

Keywords: Cisplatin, Carboplatin, Oxaliplatin, 1-10, Phenanthrolene, Spectrophotometry

Accepted on May 23, 2019

\section{Introduction}

The platinum based drugs are famous family of antiproliferative agents and were identified by Rosenberg and co-workers in 1965 . They act like alkylating agents by cross linking DNA. The parent drug cisplatin is widely used platinum based chemotherapeutic agent, whereas the carboplatin and oxaliplatin have improved toxicity profile and provide better results in germ cell, ovarian and colorectal cancers [1].

Cisplatin (Figure 1) belongs to an alkylating class of anticancer drugs and is the first member of platinum containing drugs used as antineoplastic in early 1970's. It is a divalent inorganic, water soluble platinum containing complex and is widely used due to its potent effects in the treatment of ovarian, testicular, head and neck tumor, cervical cancer and small cell lung carcinoma [2,3]. Carboplatin (Figure 1) was approved for clinical use in 1989. The mechanism of action and resistance of carboplatin are similar to cisplatin, but differs significantly in chemical, pharmacokinetic and toxicological properties [4]. Carboplatin is less reactive and well tolerated and is used as intravenous infusion to treat patients who are unable to tolerate cisplatin as front-line treatment for ovarian cancer. It is currently approved by FDA for use in the treatment of advanced ovarian and lung cancer in combination with paclitaxel or cyclophosphamide [5]. Oxaliplatin (Figure 1) is the most recent drug approved by FDA in 2002. It exhibits a wide range of antitumor activities that differ from other platinum drugs. It also suppresses the enzyme thymidylate synthetase which is also target enzyme of 5- fluorouracil, which is the reason of synergy of two drugs. It is used to treat colorectal cancers in combination with 5-fluorouracil and leucovorin [6].
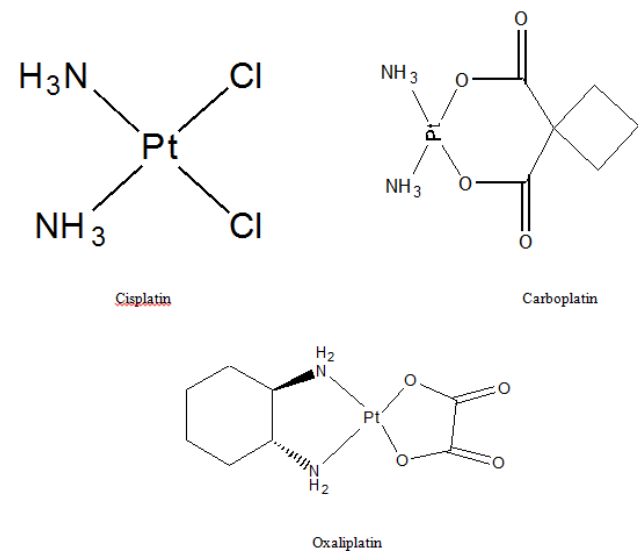

Figure 1. Structures of platinum based drugs.

Several methods for the determination of platinum based drugs include HPLC with UV detection [7,8], LC-MS [9] and ICPMS [10,11]. These platinum based drugs have also been determined by spectrophotometric method [12-14]. The previously published methods included derivitization of cisplatin or demanded costly equipment [9-11]. This work demonstrates direct and simultaneous spectroscopic method for 
the determination of platinum based drugs by spectrophotometric method.

\section{Materials and Methods}

\section{Apparatus}

A UV-visible double beam spectrophotometer (Shimadzu 1601, Japan) and 96-well plate reader, Synergy HT, USA were used to measure the absorbance.

\section{Chemicals and drugs}

Cisplatin, carboplatin and oxaliplatin were kindly gifted by Pharmedic Laboratories Pvt. Ltd. Lahore, (Pakistan). Ferric chloride, 1,10-phenanthrolene, phosphoric acid and de-ionized double distilled water were of analytic grade. Commercial injectable dosage forms of cisplatin, carboplatin and oxaliplatin were purchased from local market.

Preparation of 1,10-phenanthroline solution: 1,10Phenanthroline monohydrate $(0.4$ gram $)$ was dissolved in 100 $\mathrm{ml}$ double distilled water to form $0.4 \%$ solution.

Preparation and standardization of phosphoric acid solution: A fixed volume $(25 \mu \mathrm{l})$ of phosphoric acid of different molarity was mixed with cisplatin $(150 \mu \mathrm{g} / \mathrm{ml})$, carboplatin $(450 \mu \mathrm{g} / \mathrm{ml})$ and oxaliplatin $(150 \mu \mathrm{g} / \mathrm{ml})$ followed by the addition of $40 \mu \mathrm{l}$ of ferric chloride $(0.5 \%)$ and $100 \mu \mathrm{l}$ of $0.2 \%$ or saturated solution $(0.4 \%)$ of 1,10 -phenanthrolene solution and absorbance was measured at $510 \mathrm{~nm}$.

Ferric chloride solution: Ferric chloride (0.5 gram) was dissolved in $100 \mathrm{ml}$ double distilled water to constitute a $0.5 \%$ solution.

Standard stock solution preparation: Stock solutions of cisplatin and oxaliplatin $(1000 \mu \mathrm{g} / \mathrm{ml})$ were prepared by dissolving accurately weighed $10 \mathrm{mg}$ in double distilled water and making the volume to $10 \mathrm{ml}$ in standard volumetric flask. Carboplatin was prepared by dissolving accurately weighed 30 $\mathrm{mg}$ in $10 \mathrm{ml}$ of double distilled water to get a concentration of $3.0 \mathrm{mg} / \mathrm{ml}$. Working solutions of lower concentration was prepared by further dilution of standard stock solutions with de-ionized double distilled water.

Sample preparation: A commercial brand of cisplatin injection (Unistin-Korea), carboplatin injection (CytocarbCipla) and oxaliplatin injection (Oxilitin- Pharm Evo) were chosen.

\section{Results}

\section{Absorption spectrum of coloured complex}

The absorption spectra of cisplatin, carboplatin and oxaliplatin are shown in Figures 2-5.

\section{Chemistry of coloured complex}

The present method was based on the formation of red coloured complex with ferric chloride after its reduction to ferrous form. This complex resulting from platinum based drugs may be due to the fact that each of the two nitrogen atoms has an unshared pair of electrons that can be shared with Fe (II) ion formed by the reaction of platinum with Fe (III). Three molecules of 1,10-phenanthroline attach themselves by means of dative bonds to form ferroin complex.

\section{Method Development}

A spectroscopic method was developed in pure and applied on injectable brands of platinum based drugs as follows.

\section{Procedure}

Aliquots of working standard solutions (cisplatin, carboplatin and oxaliplatin) of $5,10,20,40$ and $60 \mu \mathrm{l}$ were added in triplicate in 96 well-plates with $40 \mu \mathrm{l}$ of $0.5 \%$ ferric chloride and $100 \mu \mathrm{l}$ of $0.2 \%$ or saturated solution $(0.4 \%)$ of 1,10 phenanthrolene. Contents were incubated at $60^{\circ} \mathrm{C}$ for 45 minutes, cooled at room temperature followed by addition of $25 \mu \mathrm{l}$ of $15 \mathrm{mM}$ phosphoric acid. Finally, the solution was mixed thoroughly and absorbance was measured at $510 \mathrm{~nm}$ against the blank prepared under same identical conditions and calibration curves were constructed (Figure 2). The system was attached with computer software (Gen 5) to analyze and calculate data (Tables 1 and 2).

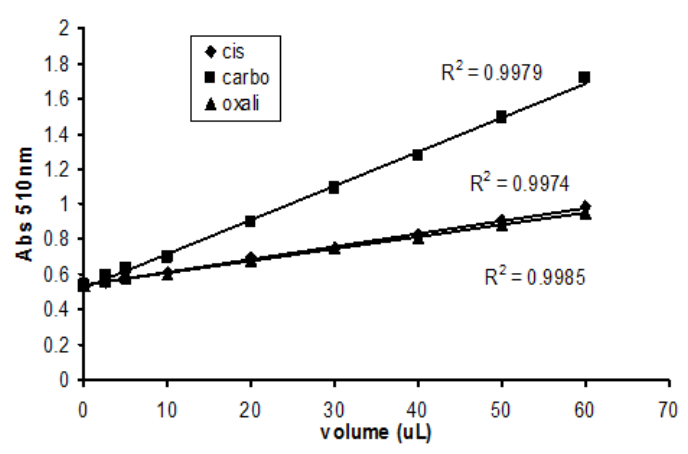

Figure 2. Calibration curve of cisplatin, carboplatin and oxaliplatin.

Table 1. Spectrophotometric determination of platinum based drugs.

\begin{tabular}{|c|c|c|c|c|c|}
\hline $\begin{array}{l}\text { Cisplatin } \\
(\mu \mathrm{g})\end{array}$ & $\begin{array}{l}\text { Abs. of } \\
\text { cisplatin } \\
\text { at } \\
510 \mathrm{~nm}\end{array}$ & $\begin{array}{l}\text { Carboplatin } \\
(\mu \mathrm{g})\end{array}$ & $\begin{array}{l}\text { Abs. of } \\
\text { carboplatin } \\
\text { at } 510 \mathrm{~nm}\end{array}$ & $\begin{array}{l}\text { Oxaliplatin } \\
(\mu \mathrm{g})\end{array}$ & $\begin{array}{l}\text { Abs. of } \\
\text { oxaliplatin } \\
\text { at } 510 \mathrm{~nm}\end{array}$ \\
\hline 0 & 0.543 & 0 & 0.543 & 0 & 0.543 \\
\hline 0.25 & 0.563 & 7.5 & 0.591 & 0.5 & 0.564 \\
\hline 0.5 & 0.589 & 15 & 0.638 & 1 & 0.583 \\
\hline 1 & 0.609 & 30 & 0.703 & 2 & 0.599 \\
\hline 2 & 0.701 & 60 & 0.898 & 4 & 0.679 \\
\hline 3 & 0.749 & 90 & 1.091 & 6 & 0.751 \\
\hline
\end{tabular}




\begin{tabular}{llllll}
\hline 4 & 0.828 & 120 & 1.276 & 8 & 0.808 \\
\hline 5 & 0.905 & 150 & 1.493 & 10 & 0.878 \\
\hline 6 & 0.987 & 180 & 1.717 & 12 & 0.952 \\
\hline
\end{tabular}

Table 2. Absorbance $(510 \mathrm{~nm})$ of cisplatin, carboplatin and oxaliplatin vs concentration $(\mu \mathrm{g} / \mathrm{ml})$.

\begin{tabular}{|c|c|c|c|c|c|}
\hline $\begin{array}{l}\text { Sample } \\
(\mu \mathrm{I})\end{array}$ & $\begin{array}{l}\text { Water } \\
(\mu \mathrm{l})\end{array}$ & $\begin{array}{l}0.5 \% \\
\mathrm{FeCl}_{3} \\
(\mu \mathrm{l})\end{array}$ & $\begin{array}{l}0.4 \% \quad 1,10- \\
\text { Phenanthrolene } \\
\text { ( } \mu \mathrm{l})\end{array}$ & & $\begin{array}{l}15 \mathrm{mM} \\
\mathrm{H}_{3} \mathrm{PO}_{4} \\
(\mu \mathrm{l})\end{array}$ \\
\hline 0 & 60 & 40 & 100 & & 25 \\
\hline 2.5 & 57.2 & 40 & 100 & & 25 \\
\hline 5 & 55 & 40 & 100 & & 25 \\
\hline 10 & 50 & 40 & 100 & & 25 \\
\hline 20 & 40 & 40 & 100 & & 25 \\
\hline 30 & 30 & 40 & 100 & & 25 \\
\hline 40 & 20 & 40 & 100 & & 25 \\
\hline 50 & 10 & 40 & 100 & \multirow{2}{*}{$\begin{array}{l}\text { Heated at } 60^{\circ} \mathrm{C} \\
\text { for } 45 \text { minutes }\end{array}$} & 25 \\
\hline 60 & 0 & 40 & 100 & & 25 \\
\hline
\end{tabular}

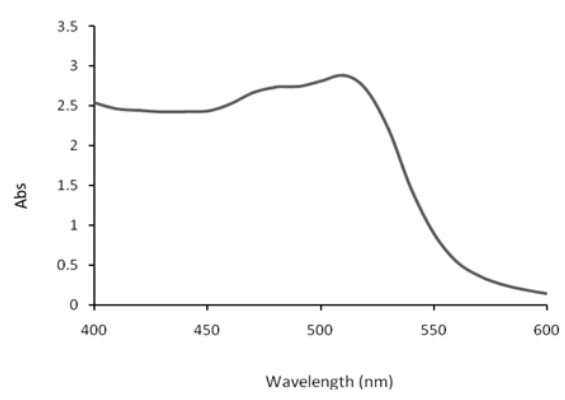

Figure 3. Spectrum of cisplatin $\left(\lambda_{\max } 510 \mathrm{~nm}\right)$

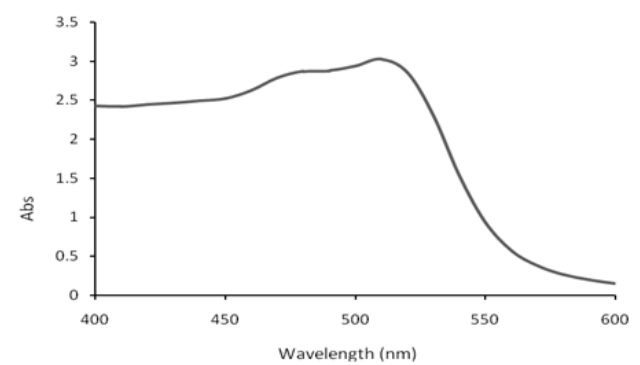

Figure 4. Spectrum of carboplatin $\left(\lambda_{\max } 510 \mathrm{~nm}\right)$.

\section{Method validation}

The developed spectrophotometric method was standardized validated with following parameters.

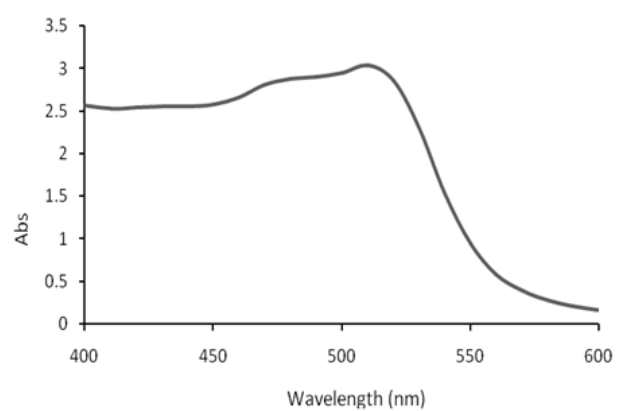

Figure 5. Spectrum of oxaliplatin $\left(\lambda_{\max } 510 \mathrm{~nm}\right)$.

Linearity and range: Linearity of the method was determined by constructing calibration curves for cisplatin, carboplatin and oxaliplatin (Figure 2). The standard stock solution of cisplatin, carboplatin and oxaliplatin $(1.0 \mu \mathrm{g} / \mathrm{ml})$ were prepared in distilled water (Table 3).

Table 3. Standard curve parameters for platinum based drugs (mean values, $n=3$ ).

\begin{tabular}{llll}
\hline Drug & Slope & Intercept & $\mathbf{r}^{2}$ \\
\hline Cisplatin & 0.072 & 0.544 & 0.997 \\
\hline Carboplatin & 0.006 & 0.52 & 0.996 \\
\hline Oxaliplatin & 0.33 & 0.543 & 0.998 \\
\hline
\end{tabular}

Sensitivity: The LOQ values of cisplatin, carboplatin and oxaliplatin were $0.25,7.5$ and $0.5 \mu \mathrm{g} / \mathrm{ml}$ and LOD values of cisplatin, carboplatin and oxaliplatin were $0.12,3.75$ and 0.25 $\mu \mathrm{g} / \mathrm{ml}$, respectively (Table 4 ).

Table 4. Parameters and sensitivity (mean values, $n=3$ ).

\begin{tabular}{llll}
\hline Parameters & Cisplatin & Carboplatin & Oxaliplatin \\
\hline Colour & Red complex & Red complex & Red complex \\
\hline$\lambda_{\max }$ & $510 \mathrm{~nm}$ & $510 \mathrm{~nm}$ & $510 \mathrm{~nm}$ \\
\hline Range & $0.25-6.0 \mu \mathrm{g}$ & $7.5-180 \mu \mathrm{g}$ & $0.5-12 \mu \mathrm{g}$ \\
\hline LOD & $0.12 \mu \mathrm{g} / \mathrm{ml}$ & $3.75 \mu \mathrm{g} / \mathrm{ml}$ & $0.25 \mu \mathrm{g} / \mathrm{ml}$ \\
\hline LOQ & $0.25 \mu \mathrm{g} / \mathrm{ml}$ & $7.5 \mu \mathrm{g} / \mathrm{ml}$ & $0.5 \mu \mathrm{g} / \mathrm{ml}$ \\
\hline r-square & 0.9974 & 0.9979 & 0.9985 \\
\hline slope & 0.0724 & 0.0065 & 0.0337 \\
\hline intercept & 0.5443 & 0.5209 & 0.5433 \\
\hline Accuracy & 98.6 & 100.3 & 101.1 \\
\hline RSD (\%) & 1.1 & 1.3 & 1.8 \\
\hline
\end{tabular}

Accuracy: Accuracy was determined by selecting low, medium and high concentrations of cisplatin, carboplatin and oxaliplatin in triplicate. The mean values (low, medium and high) of accuracy for pure drugs were given in Tables 5 and 6 
for injectable dosage forms of cisplatin, carboplatin \& oxaliplatin were given in Table 7.

Table 5. Determination of between-batches accuracy.

\begin{tabular}{|c|c|c|c|c|}
\hline Drug & Parameters & LC & MC & $\mathrm{HC}$ \\
\hline & Mean & 0.2427 & 2.925 & 5.84 \\
\hline & S.D. & 0.007 & 0.079 & 0.121 \\
\hline & $\mathrm{N}$ & 9 & 9 & 9 \\
\hline & Nominal & 0.25 & 3 & 6 \\
\hline & $\% \mathrm{CV}$ & 2.986 & 2.69 & 2.069 \\
\hline \multirow[t]{6}{*}{ Cisplatin } & $\%$ Accuracy & 97.07 & 97.51 & 97.33 \\
\hline & Mean & 7.2812 & 97.267 & 176.061 \\
\hline & S.D. & 0.1413 & 0.7886 & 1.085 \\
\hline & $\mathrm{N}$ & 9 & 9 & 9 \\
\hline & Nominal & 7.5 & 100 & 180 \\
\hline & $\% \mathrm{CV}$ & 1.9407 & 0.8108 & 0.6163 \\
\hline \multirow[t]{6}{*}{ Carboplatin } & $\%$ Accuracy & 97.08 & 97.27 & 97.81 \\
\hline & Mean & 0.4892 & 5.891 & 11.809 \\
\hline & S.D. & 0.0125 & 0.1331 & 0.322 \\
\hline & $\mathrm{N}$ & 9 & 9 & 9 \\
\hline & Nominal & 0.5 & 6 & 12 \\
\hline & $\% \mathrm{CV}$ & 2.5546 & 2.2598 & 2.7264 \\
\hline Oxaliplatin & $\%$ Accuracy & 97.84 & 98.18 & 98.41 \\
\hline
\end{tabular}

Precision: Precision of the method was performed at three different concentrations (low, medium and high) in the range in triplicates. The CV with-in-batch and between batches for low, medium and high concentrations of cisplatin, carboplatin and oxaliplatin were given in Tables 5 and 6 . The values were less than $3 \%$ and within the range of FDA guidelines.

\section{Discussion}

The present study was designed to develop a spectrophotometric method for determination of platinum based drugs. Already there was a single method only for determination of oxaliplatin 14 but no single method for simultaneous determination of cisplatin, carboplatin and oxaliplatin. Hence, a direct, simple and reproducible spectrophotometric method was developed for the estimation of cisplatin, carboplatin and oxaliplatin in pure and dosage forms.

Table 6. Determination of with-in batch precision.

\begin{tabular}{|c|c|c|c|c|}
\hline Drug & Parameters & LC & MC & HC \\
\hline & Mean & 0.2427 & 2.915 & 5.861 \\
\hline & S.D. & 0.004 & 0.085 & 0.166 \\
\hline & $\mathrm{N}$ & 6 & 6 & 6 \\
\hline & Nominal & 0.25 & 3 & 6 \\
\hline & $\% \mathrm{CV}$ & 1.535 & 2.922 & 2.831 \\
\hline \multirow[t]{6}{*}{ Cisplatin } & $\%$ Accuracy & 97.07 & 97.17 & 97.68 \\
\hline & Mean & 7.2788 & 97.093 & 175.336 \\
\hline & S.D. & 0.148 & 0.553 & 0.396 \\
\hline & $\mathrm{N}$ & 6 & 6 & 6 \\
\hline & Nominal & 7.5 & 100 & 180 \\
\hline & $\% \mathrm{CV}$ & 2.027 & 0.569 & 0.226 \\
\hline \multirow[t]{6}{*}{ Carboplatin } & $\%$ Accuracy & 97.05 & 97.09 & 97.41 \\
\hline & Mean & 0.497 & 5.8512 & 11.823 \\
\hline & S.D. & 0.01 & 0.129 & 0.159 \\
\hline & $\mathrm{N}$ & 6 & 6 & 6 \\
\hline & Nominal & 0.5 & 6 & 12 \\
\hline & $\% \mathrm{CV}$ & 2.101 & 2.211 & 1.342 \\
\hline Oxaliplatin & $\%$ Accuracy & 99.37 & 97.52 & 98.52 \\
\hline
\end{tabular}

The method is based on the reaction of platinum with saturated solution $(0.4 \%)$ of 1,10 -phenanthrolene in the presence of ferric chloride, which forms a red coloured complex on heating at $60^{\circ} \mathrm{C}$ for 45 minutes and added $15 \mathrm{mM}$ phosphoric acid.

The formed complex exhibited maximum absorption at 510 $\mathrm{nm}$. This method was successfully applied on commercial brand of cisplatin injection (Unistin-Korea), carboplatin injection (Cytocarb-Cipla) and oxaliplatin injection (OxilitinPharm Evo). The method had wide linear range with good accuracy and precision (Tables 2-4).

The applicability of the developed method for assay of injectable pharmaceutical dosage form was examined and results were summarized in Table 7 . The results are highly reproducible.

Table 7. Determination of concentration of the injectable brands of cisplatin, carboplatin and oxaliplatin by forecast formula $(y=a+b x)$.

\begin{tabular}{|c|c|c|c|c|c|c|}
\hline Serial No. & Sample & File name & $\begin{array}{l}\text { Absorbance } \\
\text { at } 510 \mathrm{~nm}\end{array}$ & $\begin{array}{l}\text { Quantity quoted } \\
\text { in dosage forms } \\
(\mu \mathrm{g} / \mathrm{ml})\end{array}$ & $\begin{array}{l}\text { Quantity determined } \\
(\mu \mathrm{g} / \mathrm{ml})\end{array}$ & $\begin{array}{l}\text { Accuracy } \\
(\%)\end{array}$ \\
\hline & Cisplatin & & & & & \\
\hline 1 & Brand (Unistin) & Unistin 1 & 0.901 & 5 & 4.94 & 98.8 \\
\hline
\end{tabular}




\begin{tabular}{|c|c|c|c|c|c|c|}
\hline 2 & & Unistin 2 & 0.898 & 5 & 4.9 & 98 \\
\hline 3 & & Unistin 3 & 0.904 & 5 & 4.99 & 99.8 \\
\hline 4 & & Unistin 4 & 0.894 & 5 & 4.85 & 97 \\
\hline 5 & & Unistin 5 & 0.902 & 5 & 4.96 & 99.2 \\
\hline Mean & & & & & 4.928 & 98.6 \\
\hline SD & & & & & 0.054 & - \\
\hline RSD & & & & & 1.1 & - \\
\hline N & & & & & 5 & 5 \\
\hline 1 & & Cytocarb 1 & 1.187 & 100 & 101.02 & 101 \\
\hline 2 & & Cytocarb 2 & 1.171 & 100 & 98.66 & 98.6 \\
\hline 3 & & Cytocarb 3 & 1.194 & 100 & 102.05 & 102 \\
\hline 4 & & Cytocarb 4 & 1.183 & 100 & 100.43 & 100.4 \\
\hline 5 & & Cytocarb 5 & 1.176 & 100 & 99.39 & 99.4 \\
\hline Mean & & & & & 100.31 & 100.3 \\
\hline SD & & & & & 1.334 & - \\
\hline RSD & Carboplatin & & & & 1.3 & - \\
\hline N & brand (Cytocarb) & & & & 5 & 5 \\
\hline 1 & & Oxalitin 1 & 0.881 & 10 & 9.94 & 99.4 \\
\hline 2 & & Oxalitin 2 & 0.879 & 10 & 9.89 & 98.9 \\
\hline 3 & & Oxalitin 3 & 0.889 & 10 & 10.17 & 101.7 \\
\hline 4 & & Oxalitin 4 & 0.894 & 10 & 10.32 & 103.2 \\
\hline 5 & & Oxalitin 5 & 0.891 & 10 & 10.23 & 102.3 \\
\hline Mean & & & & & 10.11 & 101.1 \\
\hline SD & & & & & 0.187 & - \\
\hline RSD & & & & & 1.8 & - \\
\hline $\mathrm{N}$ & Oxaliplatin brand (Oxalitin) & & & & 5 & 5 \\
\hline
\end{tabular}

\section{Conclusion}

The present spectrophotometric method is found to be economical, direct, more sensitive and unique method for the simultaneous analysis of platinum based drugs (cisplatin, carboplatin, oxaliplatin) in pure and injectable dosage forms. The statistical parameters show that method has importance in quality analysis of injectable dosage forms of platinum based drugs.

\section{References}

1. Travis LB, Andersson M, Gospodarowicz M, van Leeuwen FE, Bergfeldt K, Lynch CF, Curtis RE, Kohler BA, Wiklund T, Storm H, Holowaty E, Hall P, Pukkala E, Sleijfer DT, Clarke EA, Boice JD Jr, Stovall M, Gilbert E. Treatment-associated leukemia following testicular cancer. J National Cancer Institute 2000; 92: 1165-1171.
2. Kish JA, Weaver A, Jacobs J, Cumming G, Alsarraf M. Cisplatin and 5-flurouracil infusion in patients with recurrent and disseminated epidermoid cancer of the head and neck. Cancer 1984; 53: 1819-1824.

3. Leman M, Thomas G. Is concurrent therapy and radiotherapy, the new standard of care for locally advanced cervical cancer. J Gynaecological Cancer 2001; 11: 87-99.

4. Calvert A, Egorin MJ. Carboplatin dosage formulae: Gander bias and the use of creatinine-based methodologies. Eur J Cancer 2002; 38:11-16.

5. Go RS, Adjei AA. Review of comparative Pharmacology and clinical activity of Cisplatin and carboplatin. J Clin Oncol 1999; 17: 409-422.

6. Ibrahim A, Hirschfeld S, Cohen MH, Griebel DJ, Williams GA, Pazdur R. FDA approved summaries: oxaliplatin. Oncologist 2004; 9: 8-12. 
7. Riley C M, Sternson LA, Repta AJ. High performance Liquid Chromatography of Cisplatin. J Pharm Sci 1983; 72: 351-355.

8. Rochard EBH, Griesemann E, Barthes D, Courtois P. Simultaneous high performance liquid chromatographic analysis of carboplatin and cisplatin ininfusion fluids. J Liquid Chromat Rel Tec 1993; 16: 1505-1515.

9. Burns RB, Burton RW, Albon SP, Embree L. Liquid chromatography--mass spectrometry for the detection of platinum antineoplastic complexes. J Pharm Biomed Anal 1996; 14: 367-372.

10. Olivier H, Annic C, Prierre A. Kinetic study of the reactivity between cisplatin and its monoaquo species with L-methionine. J Inorganic Biochem 1998; 71: 61-69.

11. Esteban-Fernandez D, Gomez-Gomez MM, Canan B, Verdaguer JM, Ramirez R, Palacios MA. Speciation analysis platinum antitumoral drug in impacted tissues. Talanta 2007; 72: 768-773. 1
12. Khuhawar MY, Arian GM, Shah A. Spectrophotometric determination of platinum (II) based cisplatin and carboplatin anticancer injections. Nucleus 2004; 41: 59-62.

13. Shakuntala SS. Spectrophotometric determination of traces of platinum with 5-chloro-2-hydroxy thiobenzhydrazide after extraction into molten naphthalene. Analytical Sci 2009; 26: 95-100.

14. Srinubabu G, Pundarika RD, Sridhar L, Rao JVLNS. Spectrophotometric method for determination of oxaliplatin in pure and dosage form. E-J Chem 2006; 3: 25-32.

\section{*Correspondence to}

Muhammad Munawar Hayat

Primary and Secondary Healthcare Department

Lahore

Pakistan 